\title{
IDENTIFYING RISK FACTORS OF SEVERE EARLY CHILDHOOD CARIES IN INFANTS FROM BOSNIA AND HERZEGOVINA
}

\author{
Marija Obradović ${ }^{1}$, Olivera Dolić1, Slava Sukara', Nataša Knežević ${ }^{2}$,̌eljka Kojić ${ }^{3}$ \\ 'Department of Paediatric and Preventive Dentistry, Medical Faculty, University of Banja Luka, Banja Luka, Republic of Srpska, Bosnia and \\ Herzegovina \\ ${ }^{2}$ Department of Endodontics and Restorative Dentistry, Medical Faculty, University of Banja Luka, Banja Luka, Republic of Srpska, Bosnia and \\ Herzegovina \\ ${ }^{3}$ Department of Periodontology and Oral Medicine, Medical Faculty, University of Banja Luka, Banja Luka, Republic of Srpska, Bosnia and \\ Herzegovina
}

\section{SUMMARY}

Objective: The aim of the study was to investigate risk factors for S-ECC among infants under 24 months of age living in Banja Luka, Bosnia and Herzegovina.

Methods: A cross-sectional population-based study was carried out. Considering inclusion criteria, the total sample consisted of 192 examined infants under 24 months of age. Parents/caregivers were interviewed ahead of each dental examination of children. Following data collection, outcome measures were: the presence/absence of S-ECC (children with at least one active early carious lesion on the smooth surfaces of the maxillary anterior teeth/caries-free children) and the severity of dental caries (no caries, initial caries and cavitated caries lesion).

Results: Overall results of the study indicated that $22.9 \%$ of infants had initial caries, while $12.0 \%$ (95\% Cl: 8.1-17.3) of infants had at least one cavitated carious lesion. Multivariate logistic regression analysis showed that the age of infants $(p<0.001)$ and family monthly income $(p=0.003)$ variables were statistically significant predictors for the development of caries.

Conclusions: This research found that the most important risk predictors for the development and severity (intensity) of S-ECC in infants under 24 months of age were low monthly income of parents and the infant's age.

Key words: severe, early childhood caries, risk factor, age of infants, family monthly income

Address for correspondence: M. Obradović, Department of Paediatric and Preventive Dentistry, Medical Faculty, University of Banja Luka, Bulevar Vojvode Petra Bojovića 1A, 78000 Banja Luka, Republic of Srpska, Bosnia and Herzegovina. E-mail: marija.obradovic@med.unibl.org

https://doi.org/10.21101/cejph.a6126

\section{INTRODUCTION}

According to the American and European Academies of Paediatric Dentistry (AAPD, EAPD), early childhood caries (ECC) involves presence of one or more decayed (non-cavitated or cavitated lesions), missing (due to caries) or filled teeth in children under 72 months of age $(1,2)$. Any sign of caries on the smooth surface of a tooth in children under three years of age represents a more aggressive form of this disease termed severe early childhood caries (S-ECC) $(1,2)$.

Since 1962 when Fass first described the "nursing bottle mouth", through workshop sponsored by the Centers for Disease Control and Prevention in 1994 introducing the term "early childhood caries", to the present day, definition, diagnosis, knowledge of aetiology, prevention of and therapy for this disease have considerably improved (1-3).

There are many records on the subject of ECC multiple aetiology. Earlier researches indicated a number of related risk factors which were either more or less represented $(4,5)$. They were known as primary (cariogenic microflora, substrate - fermentable carbohydrates, susceptible host) and secondary factors. Caries cannot develop without bacteria. Although, recently published paper has emphasized the existence of associated microbiome in caries initiation and progression (6), still, the most important among them are mutans streptococci (MS). Vertical transmission of this bacteria from mother to a child is well-documented $(1,5)$. There are also findings according to which horizontal transmission of these cariogenic bacteria from father or closest relatives is also possible (5). On the other hand, deciduous teeth are very susceptible to cariogenic environment especially at an early age.

Fermentable carbohydrates, unhealthy nutritional habits mainly related to breastfeeding and bottle-feeding at night, frequent meals and high intake of sugary food/drinks between meals play an inevitable role in the development of ECC (5). Moreover, there are a number of other examined factors that predispose infants to ECC and that are related to poor oral hygiene, non-use of dental services, children's general health, socioeconomic background, parental education, living conditions, race, culture, ethnicity, and many more (7-10). Specific life circumstance of participants will determine which of these factors are significant. 
Bosnia and Herzegovina (B\&H) is an upper-middle income economy, according to the World Bank latest estimate, but despite this many things are not on the level they supposed to be. This concerns preventive programme in dentistry as well as a matter of fact there is none at all. According to available research conducted in $\mathrm{B} \& \mathrm{H}$, the prevalence of $\mathrm{ECC}$ is very high, restoration rate of deciduous teeth is low $(11,12)$ and, so far, there is no data on risk factors associated with S-ECC.

The aim of this study is to investigate risk factors for S-ECC among infants under 24 months of age living in Banja Luka, Bosnia and Hercegovina.

\section{MATERIALS AND METHODS}

A cross-sectional population-based study was carried out in the city of Banja Luka, the second largest city in B\&H, with a population of 180,053 according to the National Institute of Statistics latest census from 2013 (13).

The survey included infants under 24 months of age. Dental examination of children and parental interviews took place in the public healthcare centre (PHCC) in Banja Luka between July 2012 and July 2013. This is the only centre of primary health care in Banja Luka. The Ethical Committee (protocol number 01-1643) of the public healthcare centre in Banja Luka gave required approval for the research.

\section{Sample}

Classification of the study sample size took into account prevalence rate of $13.46 \%$ for S-ECC (diagnosed at cavitated level) obtained few years earlier among children under three years of age from Banja Luka (14), confidence interval of $95 \%$ and standard error of $5 \%$. The minimum size established was approximately 179 infants under 24 months of age.

This age group of children did not attend any preventive or educational oral health programme in Banja Luka nor did any of the children have a dental examination before.

\section{Sampling Technique}

The inclusion criteria of the study involved existence of at least two fully erupted primary maxillary teeth in a healthy child and parental consent for participation. Healthy children who paid regular paediatric and immunization visits to the PHCC in Banja Luka were referred to a specialist of paediatric and preventive dentistry (researcher) for the first dental examination and evaluation of risk factors for S-ECC. It was a simple random sample of all healthy children that sought consultation at the PHCC. The first dental visit of parents and children took place at a separate office near paediatric ambulance of the PHCC. The examination of children and interviewing of parents happened at the same time. Only children who met the inclusion criteria were included in the following research process.

\section{Parental Interview and Dental Caries Screening}

Parents/caregivers were interviewed ahead of each dental examination of children. A single researcher implemented the questionnaire in the form of face-to-face interviews. The research form drafted for the purpose of this study consisted of two parts. The first part contained questions related to generalities, sociodemographic characteristics, nutritional habits, and oral hygiene practice, while the second part included dental record.

Following a completed interview, every child was examined in a designated office with a good natural light (based on the examination - WHO, Oral Health Surveys: basic methods) (15). Dental examinations were carried out in "knee to knee" position where parent and dentist sat opposite each other. In that way, the child's body lay in the parent's lap while the head of the child lay in the dentist's lap. Dental mirror and periodontal probe - Community Periodontal Index (CPI) were used in oral examination. Sterile gauze swabs were used to dry teeth and remove dental biofilm. The quality of oral hygiene was evaluated by presence of visible dental biofilm and this was confirmed by scraping with the CPI probe. Gentle probing of gingival sulcus was performed in order to verify gingival inflammation (by absence or presence of gingival bleeding). Carious changes in infant's teeth were diagnosed by the International Caries Detection and Assessment System (ICDAS) used in diagnosis and recording of early "white spot" carious lesions (Code 2) to observable carious cavity (Code 3-6) (16). Every teeth surface was examined and documented in the second part of the research form.

Next to the data collection, outcome measures were: the presence/absence of S-ECC (children with at least one active early carious lesion on the smooth surfaces of the maxillary anterior teeth/caries-free children) and the severity of dental caries (no caries, initial caries and cavitated caries lesion). Predictor variables considering socio-demographic characteristic (mother's and father's employment, mother's and children's age, children's gender, living space, monthly family income, number of siblings), nutritional habits (meal frequency, more than eight meals per day, breastfeeding and bottle-feeding (with milk) at night, frequency of sugary food and salty crisps intake, use of medical syrups) and oral-hygiene habits (frequency of tooth brushing, tooth brushing before sleep, use of toothpaste, fluoride toothpaste) were acquired through interviews with parents. Predictors like gingival inflammation and dental biofilm presence in children were observed clinically. Numerical variable "children's age" was obtained in months (from 9 to 24 months), but after binary logistic regression testing it was dichotomized ( $\leq 18$ months and $>18$ months) due to statistical significance. Qualitative variable "living space" was primarily considered as an indirect indicator of socioeconomic status (in addition to "monthly income"), where higher income families were deemed as owing apartment/house, while lower income living in common household (e.g. in a family house with grandparents) or often rent a place to live.

\section{Statistical Analysis}

SPSS 16.0 for Windows were used for statistical analysis and presentation of results. The results were statistically analyzed by the Fisher's exact test, $\chi^{2}$ test (checking linear growth) and binary logistic regression. The values of $\mathrm{p}<0.05$ were considered as statistically significant values. Multivariate analysis was performed in two ways, i.e. by using binary logistic analysis which identified the criterion variable (there is/no caries) and by ordinal logistic analysis which identified three levels of the variable (no caries, 
initial caries and formed caries). Variations in the multivariate analysis model were selected based on logical and statistical criteria. In other words, the variable was included in the model if deemed as a statistically significant predictor in its own right and/or if found to be significant as a variable that could contribute to explanation of the development of caries. Power of multiple regression, for the obtained sample size, was 0.96 , with Cohen's effect size 0.15 .

\section{RESULTS}

The study evaluated 192 infants under 24 months of age examined for eligibility. Mean age was 16.5 months (standard deviation 4.60). No parent refused to participate in the study. Overall results of the study indicated that $65.1 \%$ (95\% CI: $58.1-71.5)$ were caries-free children, $22.9 \%$ (95\% CI: 17.5-29.4) of infants had initial carious lesions, while $12.0 \%$ (95\% CI: 8.1-17.3) of infants had at least one cavitated carious lesion.

Based on the analysis of S-ECC distribution related to sociodemographic characteristics there was a significant association with mother's employment $(p=0.006)$, father's employment $(p=0.017)$, children's age $(p<0.001)$, living space $(p<0.001)$, family monthly income $(\mathrm{p}<0.001)$, and number of siblings $(\mathrm{p}=0.018)($ Table 1$)$.

According to Table 2, most nutritional variables were related to S-ECC presence. There was an association with higher meal frequency $(p<0.001)$, intake of more than eight meals per day $(\mathrm{p}<0.001)$, breastfeeding/bottle-feeding at night $(\mathrm{p}=0.005$; $\mathrm{p}=0.041)$, frequency of sugary food/salty crisps intake $(\mathrm{p}<0.001$; $\mathrm{p}=0.020)$ and use of medical syrups for more than three months $(p=0.011)$.

Table 1. Distribution of S-ECC according to socio-demographic characteristics $(N=192)$

\begin{tabular}{|c|c|c|c|}
\hline \multirow[b]{2}{*}{ Variable } & \multicolumn{2}{|c|}{ S-ECC } & \multirow[b]{2}{*}{ p-value } \\
\hline & $\begin{array}{c}\text { Yes } \\
\mathrm{n}(\%)\end{array}$ & $\begin{array}{c}\text { No } \\
n(\%)\end{array}$ & \\
\hline \multicolumn{4}{|l|}{ Mother's employment } \\
\hline Full-time employment $(n=109)$ & $29(26.6)$ & $80(73.4)$ & \multirow{2}{*}{$0.006^{*}$} \\
\hline Part-time or unemployed $(n=83)$ & $38(45.8)$ & $45(54.2)$ & \\
\hline \multicolumn{4}{|l|}{ Father's employment } \\
\hline Full-time employment $(n=159)$ & $51(32.1)$ & $108(67.9)$ & \multirow{2}{*}{$0.017^{*}$} \\
\hline Part-time or unemployed $(n=33)$ & $16(48.5)$ & $17(51.5)$ & \\
\hline \multicolumn{4}{|l|}{ Mather's age } \\
\hline$\leq 25$ years old $(n=34)$ & $13(38.2)$ & $21(61.8)$ & \multirow{3}{*}{0.904} \\
\hline $26-30$ years old $(n=85)$ & $29(34.1)$ & $56(65.9)$ & \\
\hline$>30$ years old $(n=73)$ & $25(34.2)$ & $48(65.8)$ & \\
\hline \multicolumn{4}{|l|}{ Children's age } \\
\hline$\leq 18$ months $(n=151)$ & $33(21.9)$ & $118(78.1)$ & \multirow{2}{*}{$<0.001^{*}$} \\
\hline$>18$ months $(n=41)$ & $34(82.9)$ & $7(17.1)$ & \\
\hline \multicolumn{4}{|l|}{ Children's gender } \\
\hline Male $(n=99)$ & $35(35.4)$ & $64(64.6)$ & \multirow{2}{*}{1.00} \\
\hline Female $(n=93)$ & $32(34.4)$ & $61(65.6)$ & \\
\hline \multicolumn{4}{|l|}{ Place of living } \\
\hline Owning apartment/house $(n=90)$ & $22(24.4)$ & $68(75.6)$ & \multirow{3}{*}{$<0.001^{*}$} \\
\hline Common household $(n=70)$ & $26(37.1)$ & $44(62.9)$ & \\
\hline Rented place $(n=32)$ & $19(59.4)$ & $13(40.6)$ & \\
\hline \multicolumn{4}{|l|}{ Monthly family income } \\
\hline$<500$ BAM $(255.65 €)(n=31)$ & $16(51.6)$ & $15(48.4)$ & \multirow{4}{*}{$<0.001$} \\
\hline $500-1,100$ BAM $(255.65-562.42 €)(n=64)$ & $27(42.2)$ & $37(57.8)$ & \\
\hline $1,100-2,000$ BAM $(562.42-1,022.58 €)(n=58)$ & $19(32.8)$ & $39(67.2)$ & \\
\hline$>2,000 \operatorname{BAM}(1,022.58 €)(n=39)$ & $5(12.8)$ & $34(87.2)$ & \\
\hline \multicolumn{4}{|l|}{ Number of siblings } \\
\hline Only child $(n=104)$ & $27(26.0)$ & $77(74.0)$ & \multirow{3}{*}{$0.018^{*}$} \\
\hline One sibling $(n=76)$ & $35(46.1)$ & $41(53.9)$ & \\
\hline Two or more siblings $(n=12)$ & $5(41.7)$ & $7(58.3)$ & \\
\hline
\end{tabular}

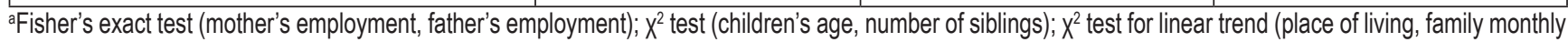
income); " statistically significant result $(p<0.05)$; BAM - Bosnian convertible marks 
Table 2. Distribution of S-ECC according to nutritional habits $(N=192)$

\begin{tabular}{|c|c|c|c|}
\hline \multirow[b]{2}{*}{ Variable } & \multicolumn{2}{|c|}{ S-ECC } & \multirow[b]{2}{*}{$\mathrm{p}$-value ${ }^{\mathrm{a}}$} \\
\hline & $\begin{array}{c}\text { Yes } \\
\mathrm{n}(\%)\end{array}$ & $\begin{array}{c}\text { No } \\
\mathrm{n}(\%)\end{array}$ & \\
\hline \multicolumn{4}{|l|}{ Meal frequency } \\
\hline Average number of meals per day & $7.0(S D=1.8)$ & $6.2(\mathrm{SD}=1.2)$ & $<0.001^{*}$ \\
\hline \multicolumn{4}{|l|}{ More than eight meals per day } \\
\hline No $(n=154)$ & $41(26.6)$ & $113(73.4)$ & \multirow{2}{*}{$<0.001^{*}$} \\
\hline Yes $(n=38)$ & $26(68.4)$ & $12(31.6)$ & \\
\hline \multicolumn{4}{|l|}{ Breastfeeding at night } \\
\hline Yes $(n=58)$ & $29(50.0)$ & $29(50.0)$ & \multirow{2}{*}{$0.005^{*}$} \\
\hline No $(n=134)$ & $38(28.4)$ & $96(71.6)$ & \\
\hline \multicolumn{4}{|l|}{ Bottle-feeding (with milk) at night } \\
\hline Yes $(n=24)$ & $13(54.2)$ & $11(45.8)$ & \multirow{2}{*}{$0.041^{*}$} \\
\hline No $(n=168)$ & $54(32.1)$ & $114(67.9)$ & \\
\hline \multicolumn{4}{|l|}{ Frequency of sugary food intake } \\
\hline$<3$ times daily $(n=182)$ & $58(31.9)$ & $124(68.1)$ & \multirow{2}{*}{$<0.001^{*}$} \\
\hline$\geq 3$ times daily $(n=10)$ & $9(90.0)$ & $1(10.0)$ & \\
\hline \multicolumn{4}{|l|}{ Frequency of salty crisps intake } \\
\hline$<3$ times daily $(n=186)$ & $62(33.3)$ & $124(66.7)$ & \multirow{2}{*}{$0.020^{*}$} \\
\hline$\geq 3$ times daily $(n=6)$ & $5(83.3)$ & $1(16.7)$ & \\
\hline \multicolumn{4}{|c|}{ Use of medical syrups more than 3 month } \\
\hline Yes $(n=15)$ & $10(66.7)$ & $5(33.3)$ & \multirow{2}{*}{$0.011^{*}$} \\
\hline No $(n=177)$ & $57(32.2)$ & $120(67.8)$ & \\
\hline
\end{tabular}

aFisher's exact test (breastfeeding/bottle-feeding with milk at night, frequency of sugary food/salty crisps intake, use of medical syrups); binary logistic regression (meal frequency); *statistically significant result $(p<0.05)$

The prevalence of S-ECC was not associated with variables presenting infant's oral hygiene habits. However, existence of dental biofilm $(\mathrm{p}<0.001)$ and gingival inflammation $(\mathrm{p}<0.001)$ in infants with S-ECC was statistically significant (Table 3 ).

In this model multivariate logistic regression analysis showed that the age of infants $(p<0.001)$ and family monthly income $(p=0.003)$ variables were statistically significant predictors for the development of caries (Table 4). Both tests (binary and ordinal logistic regression) had good characteristics in terms of classification accuracy $(84.9 \%$ and $75.0 \%)$ although, model was less able to distinguish caries intensity, for this reason there was a lower percentage for ordinal regression.

\section{DISCUSSION}

This study indicated that a child's age at the dental examination and parents' income are the only consistent and statistically significant predictors of S-ECC risk. Older children have more teeth and therefore more caries. However, this research specified that chances for caries increase by $50 \%$ from 18 months of age onwards. Keeping in mind that examined infants under 24 months of age in our study never had a dental exam before and there is neither local nor a national strategy for ECC prevention in B\&H, such drastic increase can be expected. Compared to our finding Zhou et al. showed a late onset of ECC observed in children 20 months of age, longitudinally, they find a big increase in disease prevalence between the ages of 26 and 32 months (11.1 and $28.4 \%$, respectively) (17). Rosenblatt and Zarzar evaluated the prevalence and risk factors of ECC among 12- and 36-month-old children, and also find a significant relationship between the age of children and dental caries (18). A recent Canadian review study shows that childhood age was one of the strongest independent predictor of S-ECC, in addition, it confirms increased odds of developing decay in children who do not have their first dental visit before 24 months of age (19).

Lower family monthly income is found to be connected to a higher prevalence and intensity of S-ECC at infancy according to our study. This factor, among others, represents a socioeconomic background. Generally, ECC aetiology cannot be discussed without mentioning the socioeconomic aspect supported by different variables. Tušek et al. find higher rates of ECC in ethnic minorities in the South Backa District, Republic of Serbia (9). Similarly, in Rotterdam, the Netherlands, caries is found to be more prevalent in children living in socially disadvantaged districts (20). Investigating ECC risks in 2-year-old children in southern China, it was found that lower mother's schooling ( $\leq 12$ years vs. $\geq 12$ years) is an important risk factor (21). Maternal obesity as a form of malnutrition, evident particularly among population of low socioeconomic status, is a risk factor for unfavourable birth outcomes and developmental enamel defects that can lead to increased susceptibility to caries (22). Pierce et al. and Prakash et al. state that lower annual household income is associated with a higher prevalence of ECC $(19,23)$. On the opposite, some studies 
Table 3. Distribution of S-ECC according to infant's oral hygiene habits $(N=192)$

\begin{tabular}{|c|c|c|c|}
\hline \multirow[b]{2}{*}{ Variable } & \multicolumn{2}{|c|}{ S-ECC } & \multirow[b]{2}{*}{$p$-value ${ }^{a}$} \\
\hline & $\begin{array}{c}\text { Yes } \\
\text { n (\%) }\end{array}$ & $\begin{array}{c}\text { No } \\
\text { n (\%) }\end{array}$ & \\
\hline \multicolumn{4}{|l|}{ Frequency of tooth brushing } \\
\hline$<1$ time daily $(n=130)$ & $46(35.4)$ & $84(64.6)$ & \multirow{3}{*}{0.600} \\
\hline 1 time daily $(n=46)$ & $17(37.0)$ & $29(63.0)$ & \\
\hline 2 to 3 times daily $(n=16)$ & $4(25.0)$ & $12(75.0)$ & \\
\hline \multicolumn{4}{|l|}{ Tooth brushing before sleep } \\
\hline Never or seldom $(n=155)$ & $59(38.1)$ & $96(61.9)$ & \multirow{3}{*}{0.062} \\
\hline Mostly $(n=21)$ & $5(23.8)$ & $16(76.2)$ & \\
\hline Every day $(n=16)$ & $3(18.8)$ & $13(81.3)$ & \\
\hline \multicolumn{4}{|l|}{ Use of toothpaste } \\
\hline Yes $(n=25)$ & $11(44.0)$ & $14(56.0)$ & \multirow{2}{*}{0.369} \\
\hline No $(n=167)$ & $56(33.5)$ & $111(66.5)$ & \\
\hline \multicolumn{4}{|l|}{ Fluoride toothpaste } \\
\hline Yes $(n=17)$ & $3(17.6)$ & $14(82.4)$ & \multirow{2}{*}{0.181} \\
\hline No $(n=175)$ & $64(36.6)$ & $111(63.4)$ & \\
\hline \multicolumn{4}{|l|}{ Gingival inflammation } \\
\hline Yes $(n=52)$ & $44(84.6)$ & $8(15.4)$ & \multirow{2}{*}{$<0.001^{*}$} \\
\hline No $(n=140)$ & $23(15.6)$ & $117(86.3)$ & \\
\hline \multicolumn{4}{|l|}{ Dental biofilm } \\
\hline Yes $(n=114)$ & $67(58.8)$ & $47(41.2)$ & \multirow{2}{*}{$<0.001^{*}$} \\
\hline No $(n=78)$ & $0(0.0)$ & $78(100.0)$ & \\
\hline
\end{tabular}

aFisher's exact test (fluoride toothpaste, use of toothpaste, gingival inflammation, dental biofilm); $\chi^{2}$ test for linear trend (frequency of tooth brushing, tooth brushing before sleep); *statistically significant result $(p<0.05)$

Table 4. Multiple logistic regression analysis of risk factors

\begin{tabular}{|c|c|c|c|c|c|c|c|}
\hline \multirow{2}{*}{ Variables } & \multicolumn{4}{|c|}{ S-ECC ${ }^{a}$} & \multicolumn{3}{|c|}{ Caries intensity ${ }^{b}$} \\
\hline & B & SE & OR $(95 \% \mathrm{Cl})^{\mathrm{d}}$ & $p$-value & B & SE & $\mathrm{p}$-value \\
\hline Age of children (months) & 0.42 & 0.08 & $1.53(1.32-1.77)$ & $<0.001^{*}$ & 0.39 & 0.05 & $<0.001^{*}$ \\
\hline Family monthly income ${ }^{c}$ & & & & $0.003^{*}$ & -2.34 & 0.61 & $<0.001^{*}$ \\
\hline 500-1,100 BAM (255.65-562.42€) & -2.97 & 0.80 & $0.05(0.01-0.25)$ & $<0.001^{*}$ & & & \\
\hline $1,100-2,000$ BAM $(562.42-1,022.58 €)$ & -1.00 & 0.57 & $0.37(0.12-1.14)$ & 0.084 & & & \\
\hline$>2,000$ BAM $(>1,022.58 €)$ & -0.63 & 0.42 & $0.53(0.24-1.21)$ & 0.131 & & & \\
\hline Eating sugary food more than three times a day & 2.77 & 1.50 & $15.92(0.85-299.70)$ & 0.065 & 1.05 & 0.78 & 0.179 \\
\hline Using toothpaste & 1.31 & 0.97 & $0.27(0.04-1.80)$ & 0.176 & -0.62 & 0.66 & 0.355 \\
\hline Number of daily meals & 0.14 & 0.17 & $1.15(0.83-1.61)$ & 0.402 & 0.06 & 0.13 & 0.663 \\
\hline Salty crisps snacking more than three times a day & 1.12 & 1.32 & $3.06(0.23-40.73)$ & 0.397 & 0.61 & 0.88 & 0.491 \\
\hline Breastfeeding or bottle-feeding (milk) at night & 0.46 & 0.36 & $1.58(0.55-4.53)$ & 0.396 & 0.28 & 0.46 & 0.535 \\
\hline Only child & 0.34 & 0.45 & $1.41(0.59-3.40)$ & 0.444 & -0.37 & 0.38 & 0.324 \\
\hline Tooth brushing before sleep & 0.64 & 0.79 & $1.90(0.40-8.90)$ & 0.418 & -0.59 & 0.73 & 0.416 \\
\hline Tooth brushing $>1$ time daily & -0.43 & 1.11 & $0.65(0.97-5.77)$ & 0.699 & -0.33 & 1.01 & 0.746 \\
\hline Gender & 0.01 & 0.46 & $1.01(0.41-2.45)$ & 0.991 & -0.13 & 0.39 & 0.745 \\
\hline$X^{2}(d f), p$-value & \multicolumn{4}{|c|}{$108.28(13), p<0.001^{*}$} & \multicolumn{3}{|c|}{$124.07(13), p<0.001^{*}$} \\
\hline$\%$ classification accuracy & \multicolumn{4}{|c|}{84.9} & \multicolumn{3}{|c|}{75.0} \\
\hline
\end{tabular}

$\mathrm{B}$ - regression coefficient; SE - standard error of regression coefficient; OR - odds ratio; BAM - Bosnian convertible marks; aresults of binary logistic regression in which the criterion variable is the existence of caries $\left(0=\right.$ no caries, $1=$ has caries); ${ }^{b}$ results of ordinal logistic regression in which the criterion variable is the degree of caries $(0=$ no caries, 1 = initial caries, 2 = cavitated caries); cresults refer to the testing of the existence of a rising trend of caries risk by comparing the group to the reference category of having family monthly income of 500 BAM or less; 'the odds ratio is shown as an increase in chances of a child having caries in the event of an increase in the number of numerical risk factors (months of age, number of daily meals) or presence of a certain value of the categorical variable (other variables) 
showing that a higher family income is associated with a high prevalence of ECC described that children are in the state to be indulged more often with sweets or other snacks (17).

Compatible with multivariate analyses, bivariate testing display that lower socioeconomic status of the family is a predisposition for the development of the disease. Namely, the dental health of children was better with better-educated parents, life in a family-owned flat and higher income of the family. This is consistent with previous research, which found the highest rates of ECC among socially disadvantaged groups, indigenous and ethnic minorities, between low levels of parents' education and low family incomes $(9,21,23,24)$. According to Rai and Tiwari, all factors of children's surroundings that directly influence upbringing can indirectly influence oral health (25). Among them are also single-parent families as well as households with many adults and children. This is in accordance with the findings of this study showing that infants who were the only child in a family had better teeth compared to families with two or more children.

Expectedly, there was a connection between eating habits and the development of S-ECC in infants under 24 months of age. More frequent eating, breastfeeding and bottle-feeding at night and more frequent intake of sugary food and drinks during the day were statistically significant. Moreover, children who took medical syrups for general medical conditions and for more than three months also had a higher prevalence of caries. Generally, children in the study region are introduced to unhealthy nutritional habits from an early age such as early introduction to sugary food, juices or salty crisps. Parents do this in ignorance of damage it can cause to their oral health or in order to please their children and calm them down without thinking of consequences. Although the WHO finds that sugars should not be added to the food of infants under 24 months of age (26), this study indicated a certain number of infants who at the infant age ate sugary food or other snacks more than three times a day.

Breastfeeding is a preferred way of nutrition while a mother's milk is perfectly balanced for the needs of a small child. Although this study found a significant statistical connection between SECC and breastfeeding at night, there are studies showing that breastfed children have smaller chances of developing S-ECC (27). Schroth et al. found that a history of breastfeeding had a protective effect showing the lower prevalence of S-ECC among breastfed children regardless of the duration of breastfeeding (27). The AAPD found that human breast milk was not epidemiologically associated with caries. However, risk factors for ECC include breastfeeding that occurs seven or more times a day after 12 months of age as well as ad libitum breastfeeding after the introduction of other dietary carbohydrates followed by inadequate oral hygiene (1).

Although it is generally recognized that poor oral hygiene is linked with the development of caries, this study and interview analyses found no relationship between oral hygiene habits and the carious process in infants under 24 months of age. Nevertheless, the presence of dental biofilm and gingival inflammation due to poor oral hygiene in examined infants are linked with S-ECC.

After the examination of the variable, there was a high number of infants under 24 months of age whose parents do not brush infant's teeth $(n=130)$, do not brush their teeth before going to sleep $(n=155)$, do not use any toothpastes $(n=167)$, and do not use fluoride toothpastes $(n=175)$. Again, this is due to the lack of timely information about caries prevention. Moreover, the water supply of Banja Luka does not fluoridate water and as far as we are aware, this is the case with all water supplies in Bosnia and Herzegovina. Fluoride is present in drinking water at a very low concentration of $0.04-0.08 \mathrm{mg} / \mathrm{L}$. This puts our children in an even more unsatisfactory position.

Discussed causes are one of the main reasons for the poor condition of oral health among the youngest population in Banja Luka. This was demonstrated by a high prevalence of early caries lesions (22\%) in infants under 24 months of age as well as by a high prevalence of formed carious cavities (12.0\%). Similar situation was observed in other upper-middle income countries, such as Brazil (in 12-36 months old children: 28.46\%) (18), China (2 years old: $27.66 \%$ ) (21), Turkey (3-6 years old: $49.6 \%$ ) (28), Bulgaria (2 years old: 40.0\%) (29), Thailand (15-19 months old: $82.8 \%$ ) (30), and Serbia (41.32 \pm 8.57 months old children $30.5 \%)(9)$.

This study has its limitations. They can be addressed on the methodological approach itself, which can never be absolutely perfect (for example, question of the validity of parental estimates in self-reports). The relatively small sample size limits the generalizability of the results in the overall B\&H child population. What else can be discussed is a multiple logistic regression model. It was supposed to show which are the most sustainable predictors, but it does not give the whole picture, probably because of a variety of mediating effects. A true image of a model accuracy would be given only by testing on a new sample.

\section{CONCLUSIONS}

This research found that the most important risk predictors for the development and severity (intensity) of S-ECC in infants under 24 months of age were low monthly income of parents and the infant's age.

\section{Acknowledgements}

We would like to express our deepest gratitude to Professor Jovan Vojinović for his guidance, enthusiastic encouragement, and useful critiques of this research work. We would also like to thank to the parents and their children for participation in our research.

\section{Conflicts of Interests}

None declared

\section{REFERENCES}

1. American Academy of Pediatric Dentistry. Policy on early childhood caries (ECC): classifications, consequences, and preventive strategies. American Academy of Pediatric Dentistry [Internet]. [cited 2019 March 27]. Available from: https://www.aapd.org/media/policies_guidelines/p_ eccclassifications.pdf.

2. Vadiakas G. Case definition, etiology and risk assessment of early childhood caries (ECC): a revisited review. Eur Arch Paediatr Dent. 2008;9(3):114-25.

3. Drury TF, Horowitz AM, Ismail AI, Maertens MP, Rozier RG, Selwitz RH. Diagnosing and reporting early childhood caries for research purposes: a report of a workshop sponsored by the National Institute of Dental and Craniofacial Research, the Health Resources and Services Administration, and the Health Care Financing Administration. J Public Health Dent. 1999;59(3):192-7. 
4. Leong PM, Gussy MG, Barrow SY, de Silva-Sanigorski A, Waters E. A systematic review of risk factors during first year of life for early childhood caries. Int J Paediatr Dent. 2013;23(4):235-50.

5. Tinanoff N, Baez RJ, Diaz Guillory C, Donly KJ, Feldens CA, McGrath $\mathrm{C}$, et al. Early childhood caries epidemiology, aetiology, risk assessment, societal burden, management, education, and policy: global perspective. Int J Paediatr Dent. 2019;29(3):238-48.

6. Philip N, Suneja B, Walsh L. Beyond Streptococcus mutans: clinical implications of the evolving dental caries etiological paradigms and its associated microbiome. Br Dental J. 2018;224:219-25.

7. Kirthiga M, Murugan, M, Saikia A, Kirubakaran R. Risk factors for early childhood caries: a systematic review and meta-analysis of case control and cohort studies. Pediatr Dent. 2019;41(2):95-112.

8. Obradović M, Dolić O, Vojinović J, Sukara S. Association between feeding habits and severe-early childhood caries in children up to 24 month old. Serb Dent J. 2016;63(3):117-24.

9. Tušek I, Carević M, Tušek J. The presence of early childhood caries among the members of different ethnic groups of the South Backa District. Vojnosanit Pregl. 2012;69(12):1046-51. (In Serbian.)

10. Hooley M, Skouteris H, Boganin C, Satur J, Kilpatrick N. Parental influence and the development of dental caries in children aged 0-6 years: systematic review of the literature. J Dent. 2012;40(11):873-85.

11. Šačić L, Marković N, Muratbegović A, Zukanović A, Kobašlija S. The prevalence and severity of early childhood caries in preschool children in the Federation of Bosnia and Herzegovina. Acta Med Acad. 2016;45(1):19-25.

12. Obradović M, Dolić O, Sukara S. Caries prevalence among 24 to 71-month old children from Banja Luka. Balk J Dent Med. 2016;20(3):168-71.

13. Republic of Srpska Institute of Statistics. Census of population, households and dwellings in Republika Srpska, 2013 [Internet]. [cited 2019 March 27]. Available from: http://www.rzs.rs.ba/static/uploads/bilteni/ popis/rezultati popisa/Results of the Census 2013.pdf. (In Serbian.)

14. Obradovic M. Oral health in children up to 6-years-old attending preschools in Banja Luka [dissertation]. Banja Luka: University of Banja Luka; 2010. (In Serbian.)

15. World Health Organization. Oral health surveys: basic methods [Internet]. 5th ed. Geneva: WHO; 2013 [cited 2019 March 27]. Available from: https://www.who.int/oral_health/publications/9789241548649/en/.

16. Banting D, Eggertsson H, Ekstrand KR. Criteria Manual: International Caries Detection and Assessment System (ICDAS II). Baltimore, Maryland: International Caries Detection and Assessment System (ICDAS) Coordinating Committee; 2005.

17. Zhou Y, Yang JY, Lo EC, Lin HC. The Contribution of life course determinants to early Childhood Caries: A 2-Year Cohort Study. Caries Res. 2012;46(2):87-94.
18. Rosenblatt A, Zarzar P. The prevalence of early childhood caries in 12-to 36-month-old children in Recife, Brazil. ASDC J Dent Child. 2002;69(3):319-24.

19. Pierce A, Singh S, Lee J, Grant C, de Jesus VC, Schroth RJ. The burden of early childhood caries in Canadian children and associated risk factors. Front Public Health. 2019;7:328.

20. van der Tas JT, Kragt L, Elfrink ME, Bertens LC, Jaddoe VW, Moll HA et al. Social inequalities and dental caries in six-year-old children from the Netherlands. J Dent. 2017;62:18-24.

21. Zhou Y, Lin HC, Lo EC, Wong MC. Risk indicators for early childhood caries in 2-year-old children in southern China. Aust Dent J. 2011;56(1):33-9.

22. Caufield PW, Li Y, Bromage TG. Hypoplasia-associated severe early childhood caries - a proposed definition. J Dent Res. 2012;91(6):544-50.

23. Prakash P, Subramaniam P, Durgesh, BH, Konde S. Prevalence of early childhood caries and associated risk factors in preschool children of urban Bangalore, India: A cross-sectional study. Eur J Dent. 2012;6(2):141-152.

24. Phantumvanit P, Makino Y, Ogawa H, Rugg-Gunn A, Moynihan P, Petersen PE, et al. WHO global consultation on public health intervention against early childhood caries. Community Dent Oral Epidemiol. 2018;46(3):280-7.

25. Rai NK, Tiwari T. Parental factors influencing the development of early childhood caries in developing nations: a systematic review. Front Public Health. 2018 Mar 16;6:64. doi: 10.3389/fpubh.2018.00064.

26. World Health Organization. Guideline: sugars intake for adults and children [Internet]. 2015 [cited 2019 March 27]. Available from: https:// apps.who.int/iris/bitstream/handle/10665/149782/9789241549028_eng. pdf

27. Schroth RJ, Halchuk S, Star L. Prevalence and risk factors of caregiver reported Severe Early Childhood Caries in Manitoba First Nations children: results from the RHS Phase 2 (2008-2010). Int J Circumpolar Health. 2013;72(1):21167. doi: 10.3402/ijch.v72i0.21167.

28. Ozer S, Sen Tunc E, Bayrak S, Egilmez T. Evaluation of certain risk factors for early childhood caries in Samsun, Turkey. Eur J Paediatr Dent. 2011;12(2):103-6.

29. Dimitrova MM, Kukleva MP, Kondeva VK. Prevalence of early childhood caries and risk factors in children from 1 to 3 years of age in Plovdiv, Bulgaria. Folia Med. 2002;44(1-2):60-3.

30. Vachirarojpisan T, Shinada K, Kawaguchi Y, Laungwechakan P, Somkote T, Detsomboonrat P. Early childhood caries in children aged 6-19 months. Community Dent Oral Epidemiol. 2004, 32(2):133-42.

Received February 5, 2020 Accepted in revised form November 13, 2020 